\title{
Perspective Piece \\ COVID-19 and Corticosteroids: Unfamiliar but Potentially Fatal Infections That Can Arise following Short-Course Steroid Treatment
}

\author{
Debbie-Ann Shirley* and Shannon Moonah \\ Division of Infectious Diseases and International Health, University of Virginia COVID-19 Clinic, University of Virginia Health System, Charlottesville, \\ Virginia
}

\begin{abstract}
Corticosteroid use is increasing worldwide as recent studies confer survival benefit of corticosteroids in the management of patients with severe COVID-19. Strongyloides and amebic infections are neglected diseases that can progress to catastrophic complications in patients exposed to corticosteroids, even with short treatment courses. To prevent lethal outcomes, clinicians should be aware of the threat these two parasitic infections pose to at-risk patients receiving corticosteroids, especially in the era of COVID-19.
\end{abstract}

\section{INTRODUCTION}

Corticosteroids, such as prednisone, hydrocortisone, and dexamethasone, have powerful inhibitory effects on the immune system. Patients with COVID-19 may develop severe inflammatory-mediated disease with acute lung injury and multisystem organ dysfunction. Corticosteroids may improve outcomes in seriously ill COVID-19 patients by attenuating this inappropriate host immune response. ${ }^{1-5}$

Lower 28-day mortality was demonstrated in the large prospective, open-label controlled RECOVERY trial involving 6,425 participants admitted with COVID-19 in those randomized to $6 \mathrm{mg}$ dexamethasone intravenously or orally once daily for up to 10 days than usual care. ${ }^{3}$ In those receiving invasive mechanical ventilation, mortality among those treated with dexamethasone was one-third that in those receiving usual care and in those receiving oxygen without mechanical ventilation mortality was reduced by one-fifth. ${ }^{3}$ Benefit was also seen in those treated more than 7 days after symptom onset with inflammatory lung damage, but not for those without respiratory support requirement at randomization, suggesting the timing of this intervention within the course of illness may be important. ${ }^{3}$ On this basis, the use of corticosteroids, which are relatively inexpensive and readily available medications, has increased worldwide for the treatment of patients with severe COVID-19 disease, as recommended by several health authorities such as the $\mathrm{WHO},{ }^{4}$ the $\mathrm{NIH},{ }^{6}$ and the Infectious Diseases Society of America. ${ }^{7}$ Similarly, evolving observational data also suggest that corticosteroids may be helpful in the management of the multisystem inflammatory syndrome, an uncommon but very serious complication of COVID-19 in children. ${ }^{1,8,9}$

Despite their utility, corticosteroids can be associated with significant adverse effects, often related to the dose and duration of administration as well as host-specific factors, such as underlying morbidities and concomitant medications. Prolonged systemic use of corticosteroids for more than 2 weeks can be associated with effects such as glaucoma, cataracts, adrenal suppression, hypertension, weight gain,

${ }^{*}$ Address correspondence to Debbie-Ann Shirley, Division of Infectious Diseases and International Health, University of Virginia COVID-19 Clinic, University of Virginia Health System, 1300 Jeffersen Park Avenue, P.O. Box 800386, Charlottesville, VA 22908. E-mail: ds3ru@virginia.edu psychologic effects, and gastritis. Shorter term use is better tolerated but can still lead to effects such as hyperglycemia and increased infection risk. Clinicians are likely aware of these common adverse effects of corticosteroids but may be unfamiliar with severe forms of potentially fatal parasitosis that can arise following even very brief courses. Frequently considered infections of endemic low- and middle-income countries, both Strongyloides hyperinfection syndrome and severe amebic colitis, are of global significance because of changing patterns in travel and migration. In the United States, for example, immigrants now account for nearly $15 \%$ of the population, with that percentage tripling over the past halfcentury. ${ }^{10}$ Social and economic disparities make many of the 47 million immigrants residing in the United States particularly vulnerable to SARS-CoV-2 infection. Here, we bring attention to these potentially fatal infectious risks for COVID-19 patients, especially among at-risk vulnerable populations (Table 1).

\section{STRONGYLOIDES HYPERINFECTION SYNDROME}

Strongyloides stercoralis is a soil-transmitted nematode that infects tens to hundreds of millions of people worldwide. ${ }^{11}$ Accurate estimates are limited, but studies suggest prevalence rates as high as $50 \%$ in some endemic areas, and $12 \%$ or more of immigrant populations may be infected. ${ }^{11,12}$ The U.S. Appalachian region and rural Southern United States as well as the Spanish Mediterranean coast of Southern Europe are notable examples of temperate areas that are also considered endemic. ${ }^{11,13-16}$ Infection arises when free-living filariform larvae found in human fecally contaminated soil penetrate the skin and migrate to the intestine. ${ }^{11,16}$ Following maturation, adult females lay eggs that become rhabditiform larvae excreted in the feces or develop into infective filariform larvae within the lumen that autoinfect by penetrating the intestinal mucosa, propagating chronic infection. ${ }^{11} \mathrm{~A}$ wide clinical spectrum is seen, ranging from mostly asymptomatic infection to hyperinfection syndrome with dissemination, as the larval form migrates throughout the body. ${ }^{11}$ Gramnegative bacteremia and meningitis arise as the larvae carry enteric bacteria with them during migration. ${ }^{11,16}$ Hyperinfection syndrome is associated with high mortality, approaching $90 \%$ in disseminated forms. Administration of immunosuppressive medications, such as corticosteroids, is 
TABLE 1

Suggested considerations to improve outcomes in patients with severe COVID-19 infection being treated with corticosteroids by decreasing the risk of Strongyloides hyperinfection and fulminant amebic colitis in at-risk patients

\begin{tabular}{|c|c|c|c|c|}
\hline Pathogen & Epidemiologic risk factors of infection & Clinical features of severe disease & $\begin{array}{l}\text { Evaluation in patients with } \\
\text { epidemiologic risk factors }\end{array}$ & $\begin{array}{c}\text { Strategies to treat and prevent severe } \\
\text { disease }\end{array}$ \\
\hline \multicolumn{5}{|l|}{ Helminth } \\
\hline \multirow[t]{2}{*}{$\begin{array}{c}\text { Strongyloides } \\
\text { stercoralis }\end{array}$} & \multirow[t]{2}{*}{$\begin{array}{l}\text { Skin contact with free-living } \\
\text { filariform larvae in soil } \\
\text { contaminated with human } \\
\text { feces in endemic areas }\end{array}$} & \multirow[t]{3}{*}{$\begin{array}{l}\text { Hyperinfection syndrome and } \\
\text { disseminated infection: } \\
\text { fever, dyspnea, wheezing, } \\
\text { hemoptysis, pulmonary } \\
\text { infiltrates, acute respiratory } \\
\text { distress-like syndrome, } \\
\text { anorexia, abdominal pain, } \\
\text { diarrhea, eosinophilia, } \\
\text { unexplained Gram- } \\
\text { negative bacteremia or } \\
\text { central nervous system } \\
\text { infection, septic shock }\end{array}$} & $\begin{array}{l}\text { In those with risk factors such } \\
\text { as travel to or migration } \\
\text { from an endemic area, or } \\
\text { agricultural work, obtain } \\
\text { serology. Consider stool } \\
\text { studies for ova and parasite } \\
\text { examination (submit } \\
\text { multiple stools to improve } \\
\text { sensitivity); stool PCR } \\
\text { performs better but is not } \\
\text { widely available }\end{array}$ & $\begin{array}{l}\text { Treat established or } \\
\text { suspected hyperinfection } \\
\text { syndrome with ivermectin* }\end{array}$ \\
\hline & & & $\begin{array}{l}\text { Microscopic examination of } \\
\text { body fluids, such as lower } \\
\text { respiratory samples, can } \\
\text { identify larvae }\end{array}$ & $\begin{array}{l}\text { Consider preemptive therapy } \\
\text { before the onset of } \\
\text { hyperinfection syndrome } \\
\text { with ivermectin* if no } \\
\text { contraindication† in those } \\
\text { with positive serology } \ddagger \text { or } \\
\text { diagnostic stool studies, or } \\
\text { at-risk patients not } \\
\text { previously tested } \ddagger \text { or } \\
\text { treated§ or those in } \\
\text { hyperendemic areas }\end{array}$ \\
\hline \multirow{3}{*}{$\begin{array}{l}\text { Protozoa } \\
\text { Entamoeba } \\
\text { histolytica }\end{array}$} & & & & \\
\hline & $\begin{array}{l}\text { Ingestion of infective cyst in } \\
\text { food or drink contaminated } \\
\text { with human feces in } \\
\text { endemic areas }\end{array}$ & \multirow[t]{2}{*}{$\begin{array}{l}\text { Severe and fulminant amebic } \\
\text { colitis: profuse diarrhea, } \\
\text { bloody diarrhea, bowel } \\
\text { necrosis, perforation, } \\
\text { peritonitis, shock, toxic } \\
\text { megacolon }\end{array}$} & $\begin{array}{l}\text { In those with risk factors such } \\
\text { as travel to or migration } \\
\text { from an endemic area, } \\
\text { obtain serology and antigen } \\
\text { stool studies for } E \text {. } \\
\text { histolytica or PCR when } \\
\text { available }\end{array}$ & $\begin{array}{l}\text { Treat established colitis or } \\
\text { disseminated disease with } \\
\text { metronidazole or tinidazole } \\
\text { first; follow with } \\
\text { paromomycin }\end{array}$ \\
\hline & Sexual transmission & & $\begin{array}{l}\text { Stool microscopy lacks } \\
\text { sensitivity and specificity } \\
\text { so should be avoided if } \\
\text { other modalities are } \\
\text { available, whereas antigen } \\
\text { tests have good specificity } \\
\text { but may lack sensitivity }\end{array}$ & $\begin{array}{l}\text { Treat intestinal carriage with } \\
\text { paromomycin to prevent } \\
\text { severe disease }\end{array}$ \\
\hline
\end{tabular}

${ }^{*}$ Albendazole is a second-line alternative.

†Contraindications to ivermectin generally include possible filarial coinfection such as Loa loa infection (endemic to West and central Africa), which may result in severe exacerbation of skin and eye involvement (Mazzotti reaction); age $<2$ years or weight $<15 \mathrm{~kg}$; consult an infectious diseases expert for further guidance.

$\ddagger$ Or for those who previously tested negative by serology for Strongyloides without new risk factors, retesting or preemptive re-treatment may not be needed. $\S$ If no previous documented treatment for Strongyloides stercoralis.

the most commonly identified risk factor for the development of hyperinfection syndrome, which can occur in initially asymptomatic patients. ${ }^{16,17}$ Hyperinfection may manifest as a range of gastrointestinal or pulmonary features, which are challenging to differentiate clinically from those of COVID-19 disease. About two-thirds with chronic infection may have eosinophilia. Stool and lower respiratory samples can be obtained for microscopic examination, but this method generally lacks sufficient sensitivity. ${ }^{11,18}$ Stool PCR performs better than microscopy for diagnosis, but is not widely available. In non-endemic areas, serology helps identify patients with infection but may be less useful in endemic settings where positive serology can also indicate past infection. ${ }^{11}$ Strongyloides infection should be suspected in patients with recent or remote travel history to endemic areas or those involved in agricultural work, regardless of time interval, as infection may be lifelong. Recent report of a 68-year-old immigrant from Ecuador with COVID-19 complicated by disseminated strongyloidiasis and polymicrobial septic shock following treatment including methylprednisolone exemplifies the risk. ${ }^{17}$
Ivermectin is the drug of choice for targeted treatment once the diagnosis is established. ${ }^{16}$ Given that the diagnosis can be challenging, it is reasonable to consider preemptive therapy when strong suspicion exists before corticosteroids. ${ }^{19}$ Although ivermectin may inhibit replication of SARS-CoV-2 in vitro, there are no data to support clinical use for COVID-19 treatment. ${ }^{20}$

\section{SEVERE AMEBIC COLITIS}

Amebiasis, caused by the protozoan parasite Entamoeba histolytica, infects millions of people worldwide, with multiple areas around the world continuing to observe prevalence rates exceeding $10 \% .{ }^{21}$ Transmission occurs via ingestion of infective cysts, most commonly by fecally contaminated food or water; however, sexual transmission is increasingly recognized. ${ }^{21,22}$ Following transformation within the gut, the trophozoite stage can invade the intestinal mucosa, leading to inflammatory amebic colitis or disseminate with particular predilection to forming amebic liver abscesses. ${ }^{21}$ The highest burden is among those residing in developing countries, 
although changing patterns in immigration, travel, and sexual transmission are leading to re-emergence of amebiasis in developed settings. ${ }^{21-31}$ Most cases are asymptomatic with approximately $10 \%$ of those infected developing amebic colitis, characterized by diarrhea which may be bloody. ${ }^{21}$ Severe forms of amebic colitis, though less common, are associated with high mortality. ${ }^{32}$ Colonic involvement may progress to bowel necrosis, perforation, peritonitis, shock, and toxic megacolon. ${ }^{32}$ Corticosteroid use, even brief exposure, is a known risk factor for the development of severe amebic colitis, occurring even in initially asymptomatic patients. ${ }^{32-37}$ Patients with diarrhea from amebic colitis are often misdiagnosed as having inflammatory bowel disease and inappropriately treated with steroids, prompting deterioration. ${ }^{32}$ Microscopy, which lacks sufficient sensitivity and specificity, is unable to distinguish pathogenic and nonpathogenic amebae, so alternative methods should be used for diagnosis whenever possible. ${ }^{18,21,38,39} \mathrm{~A}$ combination of serology, stool antigen, and/or molecular tests often help establish diagnosis, although serology is more difficult to interpret in endemic settings because it may indicate either past or active infection, and antigen tests may be of low sensitivity, particularly for cyst-containing stool and asymptomatic infection. ${ }^{38,40,41}$ Stool PCR is highly sensitive but use is limited in resource-poor settings. ${ }^{21,42}$ Those with symptoms should be treated with an amebicidal agent, such as metronidazole, followed by a luminal agent, such as paromomycin. ${ }^{21,43}$ Asymptomatic patients only need to be treated with a luminal agent to prevent future development of colitis and spread to uninfected persons. ${ }^{21}$

\section{CONCLUSION}

Strongyloides hyperinfection syndrome and severe amebic colitis are two potentially devastating complications that can arise in patients receiving corticosteroids, independent of dose and duration. Clinicians should consider the possibility of these parasitic infections in at-risk patients, including those with a remote history of travel to endemic areas as these severe complications can arise even years later. Algorithms for screening may be problematic if access to diagnostic testing is not readily available for those at risk; hence, further work is needed to improve the prevalence estimates of these often under-recognized and misdiagnosed infections, as well as to develop and deploy rapid, widely available diagnostics to identify in advance those most likely to benefit from antiparasitic therapy to improve poor outcomes.

Received November 13, 2020. Accepted for publication December 7 , 2020.

Published online January 6, 2021.

Acknowledgment: The American Society of Tropical Medicine and Hygiene has waived the Open Access fee for this article due to the ongoing COVID-19 pandemic.

Authors' addresses: Debbie-Ann Shirley and Shannon Moonah, Division of Infectious Diseases and International Health, University of Virginia COVID-19 Clinic, University of Virginia Health System, Charlottesville, VA, E-mails: ds3ru@virginia.edu and sm5fe@virginia.edu.

This is an open-access article distributed under the terms of the Creative Commons Attribution (CC-BY) License, which permits unrestricted use, distribution, and reproduction in any medium, provided the original author and source are credited.

\section{REFERENCES}

1. Fang FC et al., 2020. COVID-19 - lessons learned and questions remaining. Clin Infect Dis ciaa1654.

2. Fadel $\mathrm{R}$ et al., 2020. Early short course corticosteroids in hospitalized patients with COVID-19. Clin Infect Dis 71: 2114-2120.

3. Horby P et al., 2020. Dexamethasone in hospitalized patients with COVID-19 - preliminary report. N Engl J Med (Epub ahead of print).

4. Sterne J et al., 2020. Association between administration of systemic corticosteroids and mortality among critically ill patients with COVID-19: a meta-analysis. JAMA 324: 1330-1341.

5. Tomazini B et al., 2020. Effect of dexamethasone on days alive and ventilator-free in patients with moderate or severe acute respiratory distress syndrome and COVID-19: the CoDEX randomized clinical trial. JAMA 324: 1307-1316.

6. COVID-19 Treatment Guidelines Panel, 2020. Coronavirus Disease 2019 (COVID-19) Treatment Guidelines. NIAID-RML. Available at: https://www.covid19treatmentguidelines.nih.gov/. Accessed August 25, 2020.

7. Bhimraj A et al., 2020. Infectious diseases society of America guidelines on the treatment and management of patients with COVID-19. Clin Infect Dis ciaa478.

8. Dulek DE et al., 2020. Multidisciplinary guidance regarding the use of immunomodulatory therapies for acute COVID-19 in pediatric patients. J Pediatr Infect Dis Soc piaa098.

9. Jonat B et al., 2020. Multisystem inflammatory syndrome in children associated with coronavirus disease 2019 in a children's hospital in New York city: patient characteristics and an institutional protocol for evaluation, management, and follow-up. Pediatr Crit Care Med (Epub ahead of print).

10. US Census Bureau, 2019. Foreign Born: 2019 Current Population Survey Detailed Tables. Table 1.1 Population by Sex, Age, Nativity and US Citizenship Status. US Census Bureau.

11. Puthiyakunnon S, Boddu S, Li Y, Zhou X, Wang C, Li J, Chen X, 2014. Strongyloidiasis--an insight into its global prevalence and management. PLoS Negl Trop Dis 8: e3018.

12. Asundi A, Beliavsky A, Liu XJ, Akaberi A, Schwarzer G, Bisoffi Z, Requena-Méndez A, Shrier I, Greenaway C, 2019. Prevalence of strongyloidiasis and schistosomiasis among migrants: a systematic review and meta-analysis. Lancet Glob Health 7: e236-e248.

13. Russell ES, Gray EB, Marshall RE, Davis S, Beaudoin A, Handali S, McAuliffe I, Davis C, Woodhall D, 2014. Prevalence of Strongyloides stercoralis antibodies among a rural Appalachian population--Kentucky, 2013. Am J Trop Med Hyg 91: 1000-1001.

14. Singer R, Xu TH, Herrera LNS, Villar MJ, Faust KM, Hotez PJ, Aiken ARA, Mejia R, 2020. Prevalence of intestinal parasites in a low-income Texas community. Am J Trop Med Hyg 102: 1386-1395.

15. McKenna ML, McAtee S, Bryan PE, Jeun R, Ward T, Kraus J, Bottazzi ME, Hotez PJ, Flowers CC, Mejia R, 2017. Human intestinal parasite burden and poor sanitation in rural Alabama. Am J Trop Med Hyg 97: 1623-1628.

16. Krolewiecki A, Nutman TB, 2019. Strongyloidiasis: a neglected tropical disease. Infect Dis Clin 33: 135-151.

17. Lier AJ, Tuan JJ, Davis MW, Paulson N, McManus D, Campbell S, Peaper DR, Topal JE, 2020. Case report: disseminated strongyloidiasis in a patient with COVID-19. Am J Trop Med Hyg 103: 1590-1592.

18. Miller JM et al., 2018. A guide to utilization of the microbiology laboratory for diagnosis of infectious diseases: 2018 update by the Infectious Diseases Society of America and the American Society for Microbiology. Clin Infect Dis 67: e1-e94.

19. Stauffer W, Alpern J, Walker P, 2020. COVID-19 and dexamethasone: a potential strategy to avoid steroid-related strongyloides hyperinfection. JAMA (Epub ahead of print).

20. Caly L, Druce JD, Catton MG, Jans DA, Wagstaff KM, 2020. The FDA-approved drug ivermectin inhibits the replication of SARSCoV-2 in vitro. Antivir Res 178: 104787.

21. Shirley DT, Farr L, Watanabe K, Moonah S, 2018. A review of the global burden, new diagnostics, and current therapeutics for amebiasis. Open Forum Infect Dis 5: ofy 161. 
22. Huang SH et al., 2020. Ongoing transmission of Entamoeba histolytica among newly diagnosed people living with HIV in Taiwan, 2009-2018. PLoS Negl Trop Dis 14: e0008400.

23. Shirley DAT, Watanabe K, Moonah S, 2019. Significance of amebiasis: 10 reasons why neglecting amebiasis might come back to bite us in the gut. PLoS Negl Trop Dis 13: e0007744.

24. Hung CC, Chang SY, Ji DD, 2012. Entamoeba histolytica infection in men who have sex with men. Lancet Infect Dis 12: 729-736.

25. Kumanan T, Sujanitha V, Sreeharan N, 2020. Amoebic liver abscess: a neglected tropical disease. Lancet Infect Dis 20: 160-162.

26. Salit IE, Khairnar K, Gough K, Pillai DR, 2009. A possible cluster of sexually transmitted Entamoeba histolytica: genetic analysis of a highly virulent strain. Clin Infect Dis 49: 346-353.

27. Swaminathan A et al., 2009. A global study of pathogens and host risk factors associated with infectious gastrointestinal disease in returned international travellers. J Infect 59: 19-27.

28. Van Den Broucke S, Verschueren J, Van Esbroeck M, Bottieau E, Van den Ende J, 2018. Clinical and microscopic predictors of Entamoeba histolytica intestinal infection in travelers and migrants diagnosed with Entamoeba histolytica/dispar infection. PLoS Negl Trop Dis 12: e0006892.

29. Cordel H, Prendki V, Madec Y, Houze S, Paris L, Bouree P, Caumes E, Matheron S, Bouchaud O, 2013. Imported amoebic liver abscess in France. PLoS Negl Trop Dis 7: e2333.

30. Madden GR, Shirley DA, Townsend G, Moonah S, 2019. Case report: lower gastrointestinal bleeding due to Entamoeba histolytica detected early by multiplex PCR: case report and review of the laboratory diagnosis of amebiasis. Am J Trop Med Hyg 101: $1380-1383$.

31. Escola-Verge L, Arando M, Vall M, Rovira R, Espasa M, Sulleiro E, Armengol P, Zarzuela F, Barbera MJ, 2017. Outbreak of intestinal amoebiasis among men who have sex with men, Barcelona (Spain), October 2016 and January 2017. Euro Surveill 22: 30581.

32. Shirley DA, Moonah S, 2016. Fulminant amebic colitis after corticosteroid therapy: a systematic review. PLoS Negl Trop Dis 10: e0004879.
33. Wang $\mathrm{H}$, Kanthan $\mathrm{R}, 2020$. Multiple colonic and ileal perforations due to unsuspected intestinal amoebiasis-case report and review. Pathol Res Pract 216: 152608.

34. Roure S, Valerio L, Soldevila L, Salvador F, Fernandez-Rivas G, Sulleiro E, Manosa M, Sopena N, Mate JL, Clotet B, 2019. Approach to amoebic colitis: epidemiological, clinical and diagnostic considerations in a non-endemic context (Barcelona, 2007-2017). PLoS One 14: e0212791.

35. Li AA, Cholankeril G, Berry GJ, Fernandez-Becker N, 2019. An unexpected colonic mass. Am J Gastroenterol 114: 180-181.

36. Kawabe N, Sato F, Nagasawa M, Nakanishi M, Muragaki Y, 2016. An autopsy case of fulminant amebic colitis in a patient with a history of rheumatoid arthritis. Case Rep Rheumatol 2016: 8470867.

37. Kobayashi Cl, Yamamoto G, Hayashi A, Ota S, Imai Y, Fukayama M, Kurokawa M, 2011. Fatal amebic colitis after high-dose dexamethasone therapy for newly diagnosed multiple myeloma. Ann Hematol 90: 225-226.

38. Yanagawa $Y$ et al., 2020. Utility of the rapid antigen detection test E. Histolytica quik chek for the diagnosis of Entamoeba histolytica infection in nonendemic situations. J Clin Microbiol 58: e01991-20.

39. Ryan U, Paparini A, Oskam C, 2017. New technologies for detection of enteric parasites. Trends Parasitol 33: 532-546.

40. Yamamoto K, Yanagawa Y, Oka S, Watanabe K, 2020. Two cases of endoscopically diagnosed amebic colitis treated with paromomycin monotherapy. PLoS Negl Trop Dis 14: e0008013.

41. Yanagawa $Y$, Nagata N, Yagita K, Watanabe K, Okubo H, Kikuchi Y, Gatanaga H, Oka S, Watanabe K, 2020. Clinical features and gut microbiome of asymptomatic Entamoeba histolytica infection. Clin Infect Dis ciaa820.

42. Fang FC, Patel R, 2017. 2017 infectious diseases society of America infectious diarrhea guidelines: a view from the clinical laboratory. Clin Infect Dis 65: 1974-1976.

43. Gonzales MLM, Dans LF, Sio-Aguilar J, 2019. Antiamoebic drugs for treating amoebic colitis. Cochrane Database Syst Rev 1: CD006085. 